\title{
Time and Financial Transfers Within and Beyond the Family
}

\author{
Honggao Cao \\ University of Michigan
}

\begin{abstract}
Research on time and financial transfers is often conducted along two distinct lines-transfers within the family and transfers beyond the family-without considering the fact that these transfers are actually interrelated. Using longitudinal data from the Health and Retirement Study (HRS), this article investigates the links between the two groups of transfers. Transfers within and beyond the family were found to be complements. Income and wealth are strong predictors of financial transfers. Black and Hispanic families lag systematically in the generosity to help the people both within and beyond their families.
\end{abstract}

KEY WORDS: Charitable donation; family transfer; HRS; time and financial transfers; volunteer work.

Research on time and financial transfers is often conducted along two distinct lines. In one line, economists and sociologists focus on transfers within the family, arguing that such transfers are the result of altruistic preference for family members (Becker, 1974; 1991; Becker \& Tomes, 1986; Caputo, 2002; Loury, 1981; MacDonald \& Koh, 2003), or of mutual perceived advantage in transacting or engaging in joint production by the family members (Pollak, 1985; Williamson, 1979). In the other line, writers on philanthropy and non-profit work concentrate on the time and financial transfers beyond the family, studying such phenomena as charitable donations and volunteer work (Andreoni, Gale, \& Scholz, 1996; Bekkers, 2001; Callen, 1994; Carlin, 2001; Jones \& Posnett, 1991; Kitchen \& Dalton, 1990). With a few exceptions (e.g. Mulligan, 1997; Schervish \& Havens, 2003), the two lines of research have seldom intersected, leaving researchers on the transfers within the family taking as exogenous the time and financial transfers beyond the family, and researchers on philanthropy and non-profit work treating charitable donations and volunteer work as isolated decisions unrelated to the within-family transfers.

Honggao Cao, Institute for Social Research, University of Michigan, 426 Thompson Street, Ann Arbor, MI 48104, USA; e-mail: honggao@isr.umich.edu. 
Time and financial transfers within and beyond the family are clearly interrelated, however, for several obvious reasons. First, the two types of financial transfers and a family's own consumption add up, determined by the total financial resources available to each family. Other things being equal, more within-family financial transfers imply fewer resources available for decisions related to charitable donations. More charitable donations would shift the budget line inward when making decisions regarding financial transfers to children or parents. Second, the total amount of time available to each individual (and hence, to each family) is fixed. When a family has more obligations to spend time caring for their children or parents, less time is available to do volunteer work, and vice versa. In short, the withinfamily transfer and the beyond-family transfer seem to be substitutes.

Families do not have the same propensities to give, of course, due to either differential preferences or heterogeneity or both. Research shows, for example, that parents differ in their valuation of child wellbeing (Nordblom \& Ohlsson, 2003), that people with higher income and level of education are more likely to volunteer (Current Population Survey, 2002), that adults who were involved in giving and volunteerism in their youth tend to maintain that involvement in their adulthood, and that those who belong to religious organizations are more likely to volunteer and make charitable donations (Independent Sector, 2001). Thus, if differential propensities to give exist across the destinations (family and philanthropic organization) of transfers, those who are more willing to give within the family may also have high propensities to give beyond the family, suggesting that transfers within and beyond the family may also act as complements. The exact relationship between the within-family transfer and the beyond-family transfer is therefore likely to be determined by the two competing-substitution versus complementary-effects.

Understanding the empirical interrelationship between the withinfamily and the beyond-family transfers has both important theoretical and policy implications. Theoretically, by bringing together these transfers, researchers can help lay ground for any future effort to unite them in an integrated theoretical model. If the transfers are indeed strongly correlated, for example, conventional studies on intergenerational transfer or more generally on family behavior, which take as exogenous any transfers beyond family, need to be expanded. Practically, empirical evidence on the relationship between the transfers, which is currently scarce in the literature, may help the non-profit sector better understand the mechanism of individual 


\section{Honggao Cao}

giving and identify viable and reliable sources to increase the sector's sustainability.

In this article I attempt to link the time and financial transfers within the family to those beyond the family. Specifically, I use panel data from the Health and Retirement Study 1992-2000 to examine the potential correlations among all the four types of transfers. The following fundamental issues will be examined: (a) to what extent the financial transfers within the family influence the financial and time transfers beyond the family (i.e. charitable donations and volunteer work); (b) to what extent time transfers within the family influence the financial and time transfers beyond the family; (c) to what extent charitable donations influence the financial and time transfers within the family; and (d) to what extent volunteer work influences the financial and time transfers within the family. Do the transfers within the family and beyond the family behave as substitutes or complements? How do time transfers influence financial transfers-and vice versa-in a model that integrates all the four types of transfers? Do the factors influencing the transfers within the family or beyond the family play the same or similar roles in the model?

The rest of the article is organized as follows. I first review prior research integrating the transfers within and beyond the family. This review indicates that previous efforts to link these transfers are very limited. I then examine the time and financial transfer measures in the Health and Retirement Study (HRS). Several data quality problems are discussed and an overall picture of the four types of transfers is provided. In the next section, I define two levels of cross-transfer effects (the impact of one type of transfer on another) and estimate the cross-effects in various regression models. Among the results from these models, which are summarized in the Conclusion section, are evidence of complementarities between the transfers within and beyond the family, strong household income and asset effects on the financial transfers, and evidence that minority populations lag systematically in their generosity in helping the people both within and beyond the family.

\section{Prior Research Integrating Transfers Within and Beyond the Family}

Research on transfers within the family is generally isolated from that on transfers beyond the family. When studying the within-family transfers, for example, researchers often focus on why the transfers 
take place, how the transfers impact on intergenerational transmission of wealth or status, and how private transfers interact with public transfers such as social security. Conversely, when examining transfers beyond the family, researchers concentrate on who makes charitable donations, who does volunteer work, and what the relationship is between income (or wealth) and charitable giving. Although significant progress has been made in understanding the mechanisms of both within-family and beyond-family transfers, what is conspicuously missing in the literature is systematic efforts to integrate the two groups of transfers.

Among a few studies that do link the two groups of transfers, three stand out. In a simple model of utility maximization, Auten and Joulfaian (1996) saw an individual's utility as determined by his or her own consumption, the wealth or resources of child heirs, lifetime charitable contributions, and charitable bequests. The beyond-family transfers were represented in the model by lifetime charitable contributions as well as charitable bequests, whereas the within-family transfers were represented through the gifts and bequests to children that were part of children's wealth or resources. Based on this model and using matched income tax records for parents and children, they found that lifetime charitable giving and intergenerational transfers were substitutes.

A second important study integrating transfers within and beyond the family was conducted by Mulligan (1997). Extending a general framework of parental altruism, he brought together the two groups of transfers in an attempt to understand the impact of altruism on intergenerational mobility and charitable giving. In his models of transfer behavior, total resources, the value of time, and the interest rate played important part in forming parental altruism, which in turn determined not only transfers to children but also voluntary giving to charities.

The third significant study by Schervish and Havens (2003) linked the within- and beyond-family transfers. Drawing on their theoretical and empirical research on wealth and philanthropy, Schervish and Havens elaborated two directions for understanding transfers to family and charity. The first direction suggested that identification with the fate of others was the primary variable explaining transfers both within and beyond the family. In contrast to the notion in Mulligan (1997) that transfers within and beyond the family were results of altruism, this argument emphasized that individuals' caring behaviors were all motivated by a convergence of interest with the fates of others along the axis of identification versus isolation. The 


\section{Honggao Cao}

second direction implied that there was a major change in the decision-making dynamics of transfers when individuals reached a selfdefined level of financial security. According to this argument, when individuals became very rich, the tradeoffs between self and family, on the one hand, and charity on the other, were obviated. Consequently, the mechanism of the transfer behaviors was not continuous across the economic spectrum.

Although there are some studies attempting to integrate transfers within and beyond the family, current research on the issue is still very limited. Empirical evidence on the interrelationship between the two types of transfers is particularly scarce. Even in the studies linking transfers within and beyond the family, attention is constrained to financial transfers; time transfers are rarely examined. The results from the HRS reported below intend to contribute in this regard.

\section{Measuring the Time and Financial Transfers in the HRS}

The HRS, conducted biennially since 1992, is a national longitudinal survey of older (50+ years) Americans. Developed to "provide data for researchers, policy analysts, and program planners who are making major policy decisions that affect retirement, health insurance, saving and economic well-being" (Health and Retirement Study, 1999), the study contains rich information on the income and time transfers-including within-family time and financial transfers-that may affect individuals' retirement expectations, attitudes, and opportunities. It also contains rich information on individual characteristics that have been found to be significant in influencing a family's decisions on time and financial transfers. The original HRS sample is used in this analysis, ${ }^{1}$ and the observation unit is family household. ${ }^{2}$

The within-family time transfer in the HRS was measured as an aggregate of three major components: the hours spent caring for grandchildren; the hours spent helping parents eat, dress, and bathe; and the hours spent helping parents with household chores, errands, and transportation. These components, however, were not measured consistently across waves. In HRS 1992 and 1994, the time frame for measuring such transfers was "the past 12 months." Since HRS 1996, however, the time frame has been changed to "since the last interview" or "in the past 2 years." In order to achieve cross-wave comparability, I converted the measures in HRS $1996-2000^{3}$ into ones related only to "the past 12 months." The total time transfer within the family was 
thus defined as total hours spent caring for grandchildren and parents in the past 12 months.

The "2 years to 12 months conversion" procedure runs as follows. Let $X$ be the time transfer measure reported for the past 2 years or since the last interview. Let the number of the months between the current and last interviews be $n$. The new, time-frame-adjusted transfer measure, $y$, would then be calculated as $(12 X / n)$, based on a simple linear relationship between the quantity of the transfer and the reference period. ${ }^{4}$

The within-family financial transfer had two components: financial assistance given to parents and financial assistance given to children. ${ }^{5}$ Like the within-family time transfer, these components were measured inconsistently across waves. They were similarly transformed to yield 12 month measures. The total financial transfer within the family was thus defined as total financial assistance given to parents and children in the past 12 months.

The information about the transfers beyond the family in the HRS was not as rich as the information about the transfers within the family. For the financial transfer, each household was first asked whether it had made at least $\$ 500$ charitable donations in the past year, and-if the answer was yes-then how much the donations had been. For the time transfer, the most relevant measure was the hours of volunteer work done in the past 12 months for religious, educational, health-related, or other charitable organizations.

\section{Data Truncation and Cross-Wave Inconsistency}

In addition to the different time frames used for measuring the time and financial transfers within the family mentioned previously, the transfer measures in the HRS suffered from two other types of data limitations. First, in most cases, the information on the transfer variables was truncated, in the sense that it was available only when a certain threshold was exceeded. If a specific threshold was not met, then the relevant transfer measure had to be set to zero. This type of data limitation led to the mean value of the measure being downward biased. ${ }^{6}$ Second, when a truncation rule was imposed, the truncation point was not always the same across waves. The information on the hours helping grandchildren, for example, was available if a respondent had helped his or her grandchildren more than 50 hours in the past 12 months in HRS 1994, whereas the same information was available only if a respondent had helped his or her grandchildren 


\section{Honggao Cao}

more than 100 hours in the past 12 months in HRS 1992. This type of data limitation produced inconsistent transfer measures.

Although the combined impact of the two types of data limitations was unknown, it was the second type of data limitation that was likely to cause more serious problems in the analysis of the transfer data. ${ }^{7}$ Consequently, I ignored the truncation bias due to the first type of data limitation and concentrated on the inconsistencies caused by using different truncation values across waves.

In Table 1, rows $\mathrm{A}$ and $\mathrm{B}$ document the time frames and truncation values used for measuring all four types of transfer variables in HRS 1992-2000. Except for the financial transfer beyond the family, which was measured for the past 12 months and truncated at $\$ 500$ for all waves, all other types of transfers had cross-wave inconsistencies. The aggregate measure of the within-family time transfer in HRS 1992 tended to be downward biased considering that the truncation values in all the other waves were lower. By the same token, the withinfamily financial transfer tended to be downward biased in HRS 1992 but upward biased in HRS 1994, relative to the standards used in HRS 1996-2000. In addition, the time transfers beyond the family in both HRS 1992 and 1994 were also downward biased.

Table 2, row A summarizes the four types of transfers in the past 12 months in HRS 1992-2000 before corrections. Several points need to be made about these data. First, as expected, the mean values of the time transfer beyond the family was significantly downward biased in both HRS 1992 and 1994, relative to the numbers in the other HRS waves. With no truncation on the measure in HRS 1996-2000, 40\% of households reported to have done some volunteer work in the past 12 months. When the measure was truncated at 100 hours, as in HRS 1992 and 1994, the percentage was reduced to about 20, suggesting that only half of the volunteering households had done volunteer work for 100 hours or more. Second, the mean value of the time transfer within the family in HRS 1992 seemed also to be downward biased. Third, the financial transfer beyond the family, the only type of transfer measured in the same way across waves, seemed to show a very consistent time-series pattern, with the mean value of the transfer steadily increasing from $\$ 823$ in HRS 1992 to $\$ 1,298$ in HRS 2000 .

\section{Correcting for Cross-Wave Consistency}

There are two alternative ways to correct the cross-wave inconsistencies in the transfer measures in the HRS. First, with the help of 


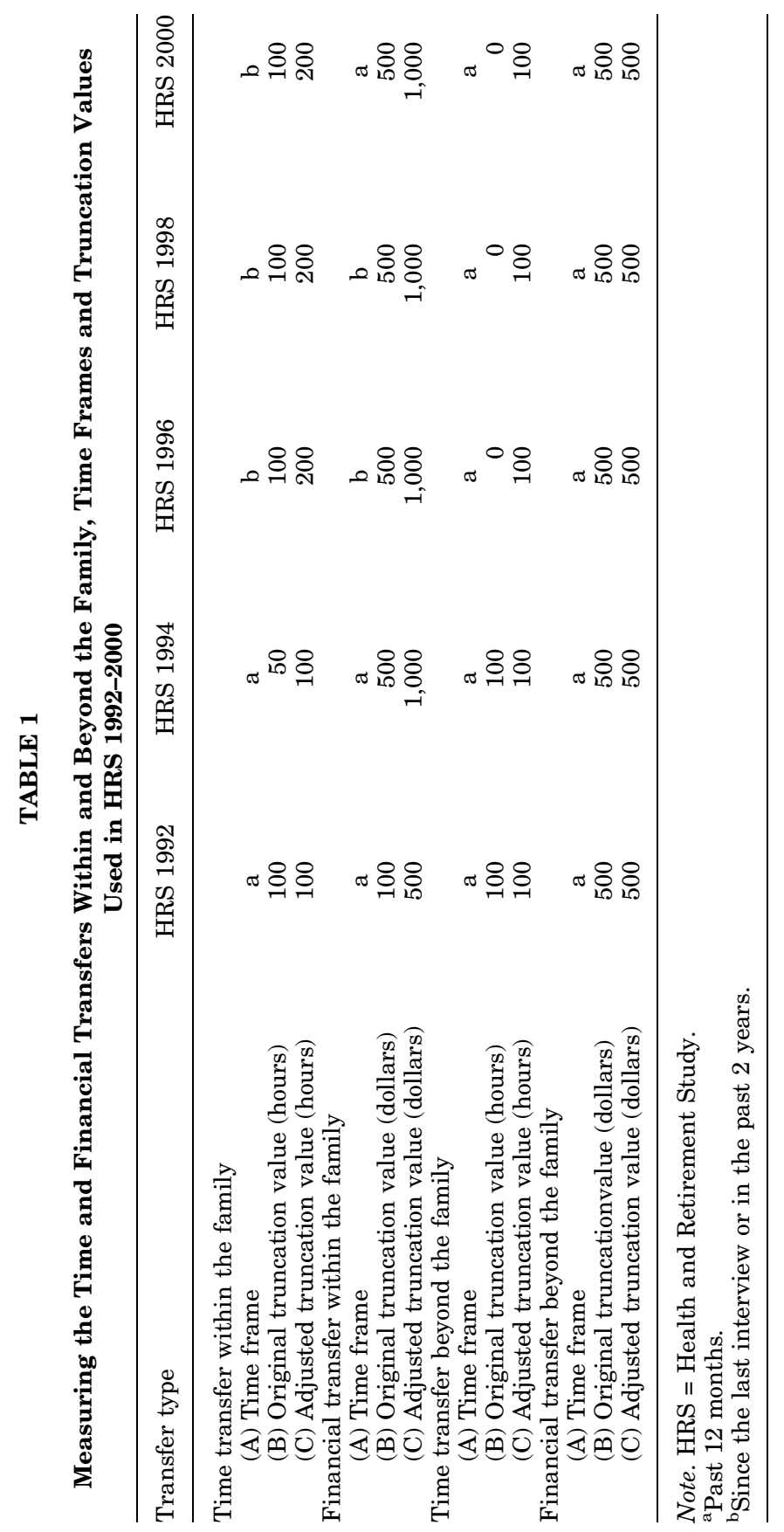




\section{Honggao Cao}

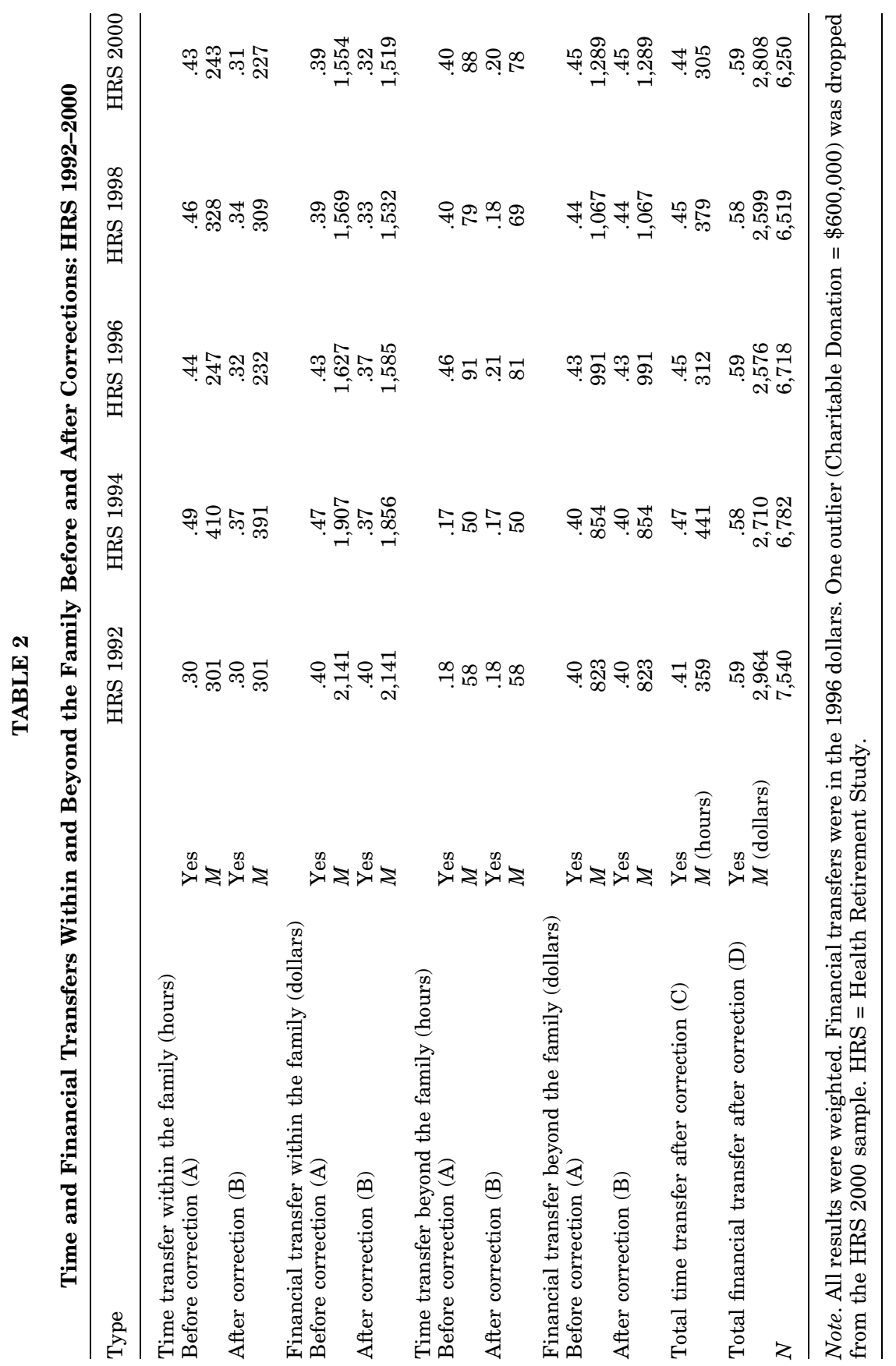


certain distributional assumptions of each transfer variable, one can get corrected mean values of the entire sample with no data truncation. Although the prospect of getting unconditional mean values for all the transfer variables is tempting, the validity of this approach critically hinges on the validity of the distributional assumptions. Second, one may get a consistent measure of each transfer variable across waves by setting a new, uniform truncation point for the variable in all the waves. Obviously, this approach does not require any distributional assumptions about the transfers. But because a new truncation point has to be set as the greatest of all the original truncation points, some of the transfer information has to be thrown away.

In this article, I used the second approach to correct the inconsistencies in the transfer variables. Specifically, I used the truncation values in HRS 1992 as the base, determining the new truncation points in other waves according to the time frames used. For the within-family financial transfer, for example, the new truncation point was $\$ 500$ in HRS 1994, when the time frame was "in the past 12 months," and \$1,000 in HRS 1996-2000, when the time frame was "in the last 2 years" or "since the last interview." Similarly, for the within-family time transfer, it was 100 hours in HRS 1994, and 200 hours in HRS 1996-2000. Because the financial transfer beyond the family had already been measured with the same truncation point in all the waves, no correction was needed for this type of transfer. The new, adjusted truncation values for each of the transfers are given in Table 1, row C.

Table 2, row B summarizes the time and financial transfers within and beyond the family in the past 12 months in HRS 1992-2000 after corrections. Compared to the results before corrections in row A, all the measures affected by the correction went in the expected direction: their mean values went down when the truncation values in HRS 1992 were used as the base. The time series patterns of the transfers, if any, were stronger and more consistent. Both the time and financial transfers within the family were declining over the 9 year period studied. For the time transfer within the family, although the percentage of households providing more than 100 hours of family care remained practically the same between HRS 1992 and 2000, the mean value of the transfer decreased by about $25 \%$, from 301 hours in HRS 1992 to 227 hours in HRS 2000. In HRS 1992, 40\% of the households provided more than $\$ 500$ financial assistance to their family members, with the mean value of the assistance being $\$ 2,141$. These numbers were $32 \%$ and $\$ 1,519$, respectively, in HRS 2000 . 


\section{Honggao Cao}

By contrast, both types of transfers beyond the family showed a nontrivial trend of increase. The financial transfer in particular exhibited a very strong increasing pattern over the HRS 1992-2000 period: The households donating at least $\$ 500$ to charities increased from $40 \%$ in HRS 1992 to $45 \%$ in HRS 2000, whereas the average donations increased by $57 \%$, from $\$ 823$ to $\$ 1,289$. Conversely, the households who had done more than 100 hours of volunteer work were $18 \%$ in HRS 1992 , and $20 \%$ in HRS 2000. Over the same period, the average hours of volunteer work increased by about 35\%, from 58 to 78 .

One immediate consequence of the diverging within and beyond the family transfer patterns was that the total time transfer, which combined the time transfers within and beyond the family, and the total financial transfer, which combined the financial transfers within and beyond the family, showed less salient time series patterns (see Table 2, rows C and D). From HRS 1992 to 2000, although the households who had made at least 100 hours of time transfer either within or beyond the family increased by about $7 \%$, the mean value of the transfer decreased by about $8 \%$. Similarly, although the percentage of households who had made at least $\$ 500$ of financial transfer either within or beyond the family remained unchanged, the mean value of the transfer decreased by about $9 \%$. These results seemed to lead to the following hypotheses:

Hypothesis 1: Time and financial transfers within and beyond the family are substitutes. More time transfer within the family leads to less time transfer beyond the family, and vice versa. Greater financial transfer within the family leads to fewer financial transfer beyond the family, and vice versa.

Hypothesis 2: As people get older, financial transfer within the family is decreasing, whereas the transfer beyond the family is increasing.

Hypothesis 3: As people get older, time transfer within the family is decreasing, whereas the transfer beyond the family is increasing.

\section{Cross-Effects in Regression Models}

In order to test the validity of the hypotheses, and more generally to understand the mechanism of the time and financial transfers within and beyond the family, I estimated a set of simple regression models. Included in each transfer model were demographic variables (e.g. age, race/ethnicity, and educational attainment) $)^{8}$, variables representing a household's economic and labor market status, and variables representing the household structure. To capture the effects of other 
transfers on the transfer as the dependent variable (or cross-transfer effects for short), all three other transfers were also included in the model.

Two levels of cross-transfer effects were defined. In the first level, the cross-transfer effect referred to the impact of one type of transfer on another type across the form of transfer (time or money) or across the destination of the transfer (within or beyond the family), but not both. Examples of this included the effect of the within-family time transfer on the within-family financial transfer, the effect of the within-family time transfer on the beyond-family time transfer, and the effect of the beyond-family financial transfer on the beyond-family time transfer. In the second level, the cross-transfer effect referred to the impact of one type of transfer on another type across both the form and the destination of transfer. Examples of this included the effect of the within-family time transfer on the beyond-family financial transfer, and the effect of the beyond-family time transfer on the withinfamily financial transfer. Empirical evidence on the signs or the magnitude of these cross-effects is scarce. Presumably, strong and positive cross-effects would suggest that the time and financial transfers within and beyond the family are complements, whereas strong and negative cross-effects imply that the transfers are substitutes.

That a household's economic and labor market status affects its transfer behavior has been well documented in the literature (Andreoni et al., 1996; Becker, 1991; Becker \& Tomes, 1986; Dettingger \& Clarkberg, 2002; Lune, Winter, Morris, Gutkowska, \& Jeżewska-Zychowicz, 1999; McClelland \& Brooks, 2004; Menchik \& Weisbrod, 1987). Wealthier parents, for example, are not only more capable of transferring their assets to their children-in the forms of both human capital investment and bequest-but also more capable of making charitable donations. Compared to those who are not very active in the labor market, individuals who have full-time jobs may have less time caring for their family members or doing volunteer work.

The variables reflecting a household economic and labor market status in the transfer models included dummy variables indicating whether an individual was working, retired, or not in labor market due to other reasons; total household assets at the time of the interview; total household income in the last calendar year; and a dummy variable indicating whether any of the household income was labor income. In accordance with the HRS income and asset definitions (Health and Retirement Study, 1991), total household assets comprised housing equities, real estate, business or farm, individual 


\section{Honggao Cao}

retirement accounts, stocks or mutual funds, certificates of deposit, bonds, checking or savings accounts, transportation vehicles, and other assets, minus debts. Total household income was calculated as the sum of labor income, income from assets, and income from any other sources defined by the HRS. Labor income included wages or salary, bonuses, tips or commissions, income from professional practice or trade, and income from a second job or self-employment.

The variables representing the household structure included the family size at the time of the 1992 entry to the HRS study, whether the household were coupled, the number of parents or parents-in-law who were still alive, the number of children, and the number of siblings. Supposedly, these variables would capture the effects of differential needs for-as well as differential abilities to contribute to-the transfers by family members. The definitions and a summary of all the independent variables in the models are given in Table 3.

\section{Single Wave Results}

Tables 4-7 list the Tobit regression results for the models estimated separately for each of the HRS data waves from 1992 to 2000. Tobit models were chosen simply because the transfer measures were all truncated. Thus, by using Tobit models, a zero value on a transfer variable was not treated as really no transfer, but as an indication that the amount of transfer was below a particular threshold. The baseline variables omitted in the models were "Other races," "Non-Hispanic," "School year=16+," and "Not in labor market—other reasons."

A strong education effect was shown in all the four transfer models and across all the HRS waves. In general, a household headed by a person with higher educational level tended to spend less time on family care but provided more financial assistance to the family members. In addition, a household headed by a person with higher educational level tended to do more volunteer work and make more charitable donations. Age played a statistically significant role only in determining the financial transfers. Older people tended to provide less financial assistance to their parents and their children but make more charitable donations.

The race/ethnicity effects were not all statistically significant. Nevertheless, the overall picture clearly suggested that the households headed by those who identified themselves as Hispanic tended to spend less time on family care and volunteer work, and the households headed by those who identified themselves as Black or Hispanic tended to provide less financial assistance to the family members. 


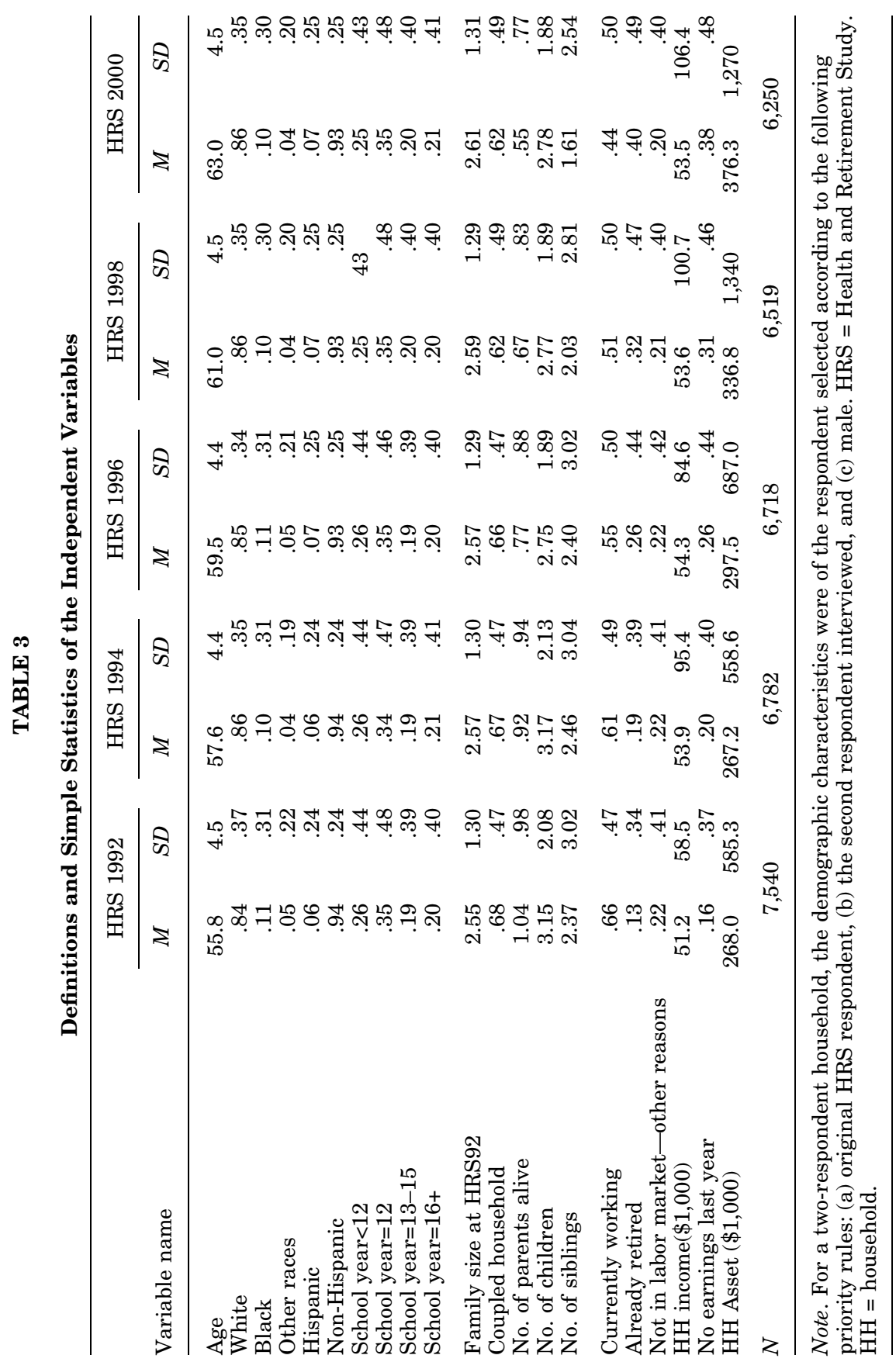




\section{Honggao Cao}

\section{TABLE 4}

Tobit Regression Coefficients in the Model Predicting the Time Transfer Within the Family

\begin{tabular}{|c|c|c|c|c|c|}
\hline Independent variable & $\begin{array}{l}\text { HRS } \\
1992\end{array}$ & $\begin{array}{l}\text { HRS } \\
1994\end{array}$ & $\begin{array}{l}\text { HRS } \\
1996\end{array}$ & $\begin{array}{l}\text { HRS } \\
1998\end{array}$ & $\begin{array}{l}\text { HRS } \\
2000\end{array}$ \\
\hline Age & 14.0 & -6.0 & -8.4 & -12.7 & -7.3 \\
\hline White & $424.1^{*}$ & 339.8 & 141.3 & 12.2 & -31.8 \\
\hline Black & -142.7 & 25.9 & $-259.4^{*}$ & -355.7 & $-413.2^{*}$ \\
\hline Hispanic & $-643.1^{*}$ & $-522.1^{* *}$ & $-415.6^{* * *}$ & $-649.3^{* * *}$ & $-585.9^{* *}$ \\
\hline School year<12 & $535.3^{* * *}$ & $328.4^{* *}$ & 64.3 & 50.5 & $267.8^{*}$ \\
\hline School year=12 & $624.7^{* * *}$ & $481.3^{* *}$ & $212.4^{* *}$ & $434.9^{* * *}$ & $436.0^{* *}$ \\
\hline School year=13-15 & $375.1^{* *}$ & 194.5 & 97.0 & 121.9 & $293.5^{* *}$ \\
\hline Family size & $123.4^{* * *}$ & $176.4^{* * *}$ & $101.8^{* * * *}$ & $214.2^{* * *}$ & $128.8^{* * *}$ \\
\hline Coupled household & $665.4^{* * *}$ & $456.7^{* * *}$ & $379.8^{* * *}$ & $372.5^{* *}$ & $349.9^{* *}$ \\
\hline No. of parents alive & $213.9^{*}$ & $527.7^{* * *}$ & $266.8^{* * *}$ & $695.8^{* * *}$ & $581.4^{* *}$ \\
\hline No. of children & $93.5^{* * *}$ & $37.0^{*}$ & $64.4^{* *}$ & $91.9^{* * *}$ & $59.9^{* * *}$ \\
\hline No. of siblings & 19.1 & 7.1 & 11.4 & $31.4^{*}$ & 13.4 \\
\hline Currently working & $-194.2^{*}$ & -68.0 & -97.0 & $-212.0^{*}$ & $-287.5^{* *}$ \\
\hline Already retired & 19.7 & $313.2^{* *}$ & $147.2^{*}$ & 159.0 & 18.3 \\
\hline HH income $(\$ 1,000)$ & $-3.5^{* *}$ & $-2.1^{* *}$ & -.9 & -.2 & -.5 \\
\hline No earnings & $-208.5^{*}$ & 68.4 & -58.0 & $170.3^{*}$ & -68.6 \\
\hline Asset $(\$ 1,000)$ & .08 & .07 & .02 & -.04 & .02 \\
\hline Money transfer within the family & $.01^{*}$ & $.01^{* *}$ & $.02^{* *}$ & $.02^{* *}$ & $.01^{* *}$ \\
\hline Charitable donation & .002 & -.008 & $-.020^{*}$ & -.001 & .001 \\
\hline Volunteer work & $.41^{* *}$ & $.52^{* * *}$ & $.28^{* * *}$ & .17 & .009 \\
\hline Intercept & $-3922.8^{* *}$ & $-2526.8^{* * *}$ & $-1295.6^{* *}$ & -2356.3 & $-796.8^{*}$ \\
\hline Pseudo $R 2$ & .011 & .008 & .011 & .010 & .011 \\
\hline
\end{tabular}

Note . No earnings $=$ no labor income in the last year. $\mathrm{HRS}=$ Health and Retirement Study. $\mathrm{HH}=$ household.

* $p=.05,{ }^{* *} p=.01$.

As expected, the household structure was an important determinant of household transfer behaviors. The bigger a household, the more time and financial transfers within the family occurred. The greater the number of living parents (or parents-in-law), the more time and financial transfers within the family occurred. In addition, a household with more children tended to spend more time on family care, and made less charitable donations. All these results suggest that the within-family transfers were probably needs-driven.

Household transfer behaviors were also influenced by household members' labor market status. Compared to others (e.g. homemakers, 
Journal of Family and Economic Issues

TABLE 5

Tobit Regression Coefficients in the Model Predicting the Financial Transfer Within the Family

\begin{tabular}{|c|c|c|c|c|c|}
\hline Independent variable & $\begin{array}{l}\text { HRS } \\
1992\end{array}$ & $\begin{array}{l}\text { HRS } \\
1994\end{array}$ & $\begin{array}{l}\text { HRS } \\
1996\end{array}$ & $\begin{array}{l}\text { HRS } \\
1998\end{array}$ & $\begin{array}{l}\text { HRS } \\
2000\end{array}$ \\
\hline $\begin{array}{l}\text { Age } \\
\text { White } \\
\text { Black } \\
\text { Hispanic } \\
\text { School year }<12 \\
\text { School year=12 } \\
\text { School year=13-15 }\end{array}$ & $\begin{array}{c}-72.5 \\
-629.1^{\text {** }} \\
-6392.2^{\text {*** }} \\
-3141.0^{\text {** }} \\
-6750.7^{\text {*** }} \\
-3687.2^{\text {*** }} \\
-2216.4^{* *}\end{array}$ & $\begin{array}{c}-162.3^{* * *} \\
348.3^{* *} \\
-4552.0^{* *} \\
-1363.0^{\text {*** }} \\
-4495.2^{* * *} \\
-2208.1^{* *} \\
-477.4\end{array}$ & $\begin{array}{c}-91.5^{*} \\
-284.7^{\text {** }} \\
-3837.1^{* *} \\
-4200.0^{* *} \\
-4374.0^{* *} \\
-2310.0^{* * *} \\
-1184.1^{\text {*** }}\end{array}$ & $\begin{array}{c}-62.8 \\
-593.7^{\text {** }} \\
-7039.6^{* *} \\
-4855.9^{\text {** }} \\
-6902.4^{\text {** }} \\
-3294.5^{\text {*** }} \\
-2281.1^{\text {** }}\end{array}$ & $\begin{array}{c}-45.9 \\
-386.1^{* *} \\
-6987.3^{* *} \\
-5196.0^{* *} \\
-6355.1^{*} \\
-3478.0^{* *} \\
-1528.8^{* *}\end{array}$ \\
\hline $\begin{array}{l}\text { Family size } \\
\text { Coupled household } \\
\text { No. of parents alive } \\
\text { No. of children } \\
\text { No. of siblings }\end{array}$ & $\begin{array}{c}1099.6^{* *} \\
-311.7^{* *} \\
1763.1^{* *} \\
279.0^{* *} \\
-149.1^{*}\end{array}$ & $\begin{array}{c}1282.5^{* *} \\
62.1^{\text {** }} \\
1939.5^{\text {* }} \\
101.9^{\text {** }} \\
-183.7^{\text {* }}\end{array}$ & $\begin{array}{c}1136.4^{* *} \\
-258.6 \\
954.4^{* *} \\
-88.3 \\
-16.5\end{array}$ & $\begin{array}{r}1311.4^{* * *} \\
-1856.9^{* *} \\
2822.5^{* *} \\
89.6 \\
-77.2\end{array}$ & $\begin{array}{c}1048.5^{* *} \\
-22.6^{* *} \\
1602.0^{* *} \\
-2.4^{* *} \\
-64.9\end{array}$ \\
\hline $\begin{array}{l}\text { Currently working } \\
\text { Already retired } \\
\text { HH income }(\$ 1,000) \\
\text { No earnings } \\
\text { Asset }(\$ 1,000)\end{array}$ & $\begin{array}{r}1941.5^{* *} \\
2284.6^{* *} \\
37.3^{* *} \\
-2741.8^{* *} \\
1.6^{* *}\end{array}$ & $\begin{array}{r}2093.2^{* * *} \\
2337.9^{* * *} \\
19.3^{* * *} \\
-1533.7^{* * *} \\
2.0^{* *}\end{array}$ & $\begin{array}{c}978.0^{* * *} \\
1037.0^{* *} \\
11.4^{* *} \\
-635.6^{* *} \\
1.4^{* *}\end{array}$ & $\begin{array}{r}858.0^{* * *} \\
2346.3^{* * *} \\
25.6^{* * *} \\
-2539.9^{* *} \\
.34^{* *}\end{array}$ & $\begin{array}{r}963.2^{* *} \\
1899.3 \\
20.3 \\
-364.4 \\
.82\end{array}$ \\
\hline Money transfer within the family & $.86^{* *}$ & $.69^{* * *}$ & $1.4^{* * *}$ & $.79^{* * *}$ & $1.1^{* *}$ \\
\hline Charitable donation & $.21^{* *}$ & $.41^{* *}$ & $.25^{* *}$ & $.21^{* *}$ & $.11^{* *}$ \\
\hline Volunteer work & $1.5^{*}$ & .61 & .46 & .64 & .30 \\
\hline Intercept & -5356.1 & -2244.0 & -1096.9 & -4700.1 & -5878.2 \\
\hline Pseudo $R 2$ & .020 & .024 & .022 & .026 & .021 \\
\hline
\end{tabular}

Note. No earnings $=$ no labor income in the last year. HRS $=$ Health and Retirement Study. $\mathrm{HH}=$ household.

${ }^{*} p=.05,{ }^{* * *} p=.01$.

disabled individuals, and those who were unemployed but looking for a job), people who were currently working tended to spend less time on family care but provided more financial assistance to family members and made more charitable donations. By contrast, people who were already retired tended to make more time and financial transfers both within and beyond the family.

The asset and income effects were strong in the models predicting the financial transfers, but trivial in the models predicting the time transfers. In general, rich or high-income households tended to make more financial transfers both within and beyond the family. Condi- 


\section{Honggao Cao}

\section{TABLE 6}

Tobit Regression Coefficients in the Model Predicting the Time Transfer beyond the Family

\begin{tabular}{|c|c|c|c|c|c|}
\hline Independent variable & $\begin{array}{l}\text { HRS } \\
1992\end{array}$ & $\begin{array}{l}\text { HRS } \\
1994\end{array}$ & $\begin{array}{l}\text { HRS } \\
1996\end{array}$ & $\begin{array}{l}\text { HRS } \\
1998\end{array}$ & $\begin{array}{l}\text { HRS } \\
2000\end{array}$ \\
\hline Age & 1.0 & -6.3 & 5.6 & 4.7 & 1.8 \\
\hline White & 148.7 & 45.1 & 39.5 & 9.6 & 123.2 \\
\hline Black & -117.3 & -168.5 & -40.9 & $-243.7^{*}$ & -143.7 \\
\hline Hispanic & $-264.3^{* * *}$ & $-172.7^{*}$ & $-205.9^{* *}$ & $-218.8^{* * *}$ & $-285.5^{* *}$ \\
\hline School year $<12$ & $-482.1^{* * *}$ & $-433.6^{* *}$ & $-543.9^{* * *}$ & $-594.9^{* * *}$ & $-774.3^{* *}$ \\
\hline School year=12 & $-274.4^{* * *}$ & $-243.6^{* *}$ & $-298.8^{* * *}$ & $-259.2^{* * *}$ & $-402.9^{* *}$ \\
\hline School year $=13-15$ & $-173.1^{* *}$ & $-86.5^{*}$ & $-137.4^{* * *}$ & $-161.3^{* *}$ & $-223.6^{* *}$ \\
\hline Family size & $28.9^{*}$ & $30.4^{*}$ & 10.4 & 10.0 & 4.0 \\
\hline Coupled household & $93.5^{*}$ & $87.1^{*}$ & $263.3^{* * *}$ & $209.1^{* * *}$ & $339.8^{* *}$ \\
\hline No. of parents alive & $-20.6^{*}$ & $-73.2^{*}$ & -61.7 & $54.0^{* *}$ & 10.7 \\
\hline No. of children & 11.9 & $12.2^{*}$ & -2.7 & $5.3^{* * *}$ & 9.8 \\
\hline No. of siblings & 4.2 & 5.5 & $13.7^{*}$ & $2.0^{*}$ & 5.0 \\
\hline Currently working & -37.1 & -7.3 & -97.0 & -20.1 & -16.6 \\
\hline Already retired & 35.2 & $175.9^{\text {**** }}$ & 147.2 & $174.4^{* * *}$ & $130.8^{*}$ \\
\hline HH income $(\$ 1,000)$ & $-.78^{*}$ & $-.40^{* *}$ & 52.0 & .01 & -.29 \\
\hline No earnings & $-33.6^{*}$ & -47.2 & 72.4 & $-17.4^{*}$ & 75.6 \\
\hline Asset $(\$ 1,000)$ & .02 & .02 & -.07 & -.01 & .02 \\
\hline Money transfer within the family & $.06^{* *}$ & $.04^{* *}$ & $.11^{* * *}$ & .03 & .03 \\
\hline Charitable donation & $.005^{* *}$ & .004 & .001 & .001 & -.001 \\
\hline Volunteer work & $.06^{* *}$ & $.05^{* * *}$ & $.02^{* * *}$ & $.04^{* *}$ & $.01^{* *}$ \\
\hline Intercept & $-971.9^{* *}$ & $-448.9^{* * *}$ & $-1101.8^{* * *}$ & $-1182.7^{* *}$ & $-1169.7^{* *}$ \\
\hline Pseudo $R 2$ & .022 & .027 & .020 & .026 & .022 \\
\hline
\end{tabular}

Note. No earnings $=$ no labor income in the last year. HRS $=$ Health and Retirement Study. $\mathrm{HH}=$ household.

${ }^{*} p=.05,{ }^{* *} p=.01$.

tional on income, households with no labor income tended to make more financial transfers.

\section{Cross-Effects}

The correlations between one type of transfer on the other for the same transfer form or for the same transfer destination were strong, as indicated in Table 8, which summarizes the 12 possible cross-effects based on the single wave regression results in Tables 4-7. All eight Level-1 cross-effects were positive and statistically significant, sug- 
Journal of Family and Economic Issues

TABLE 7

Tobit Regression Coefficients in the Model Predicting the Financial Transfer Beyond the Family

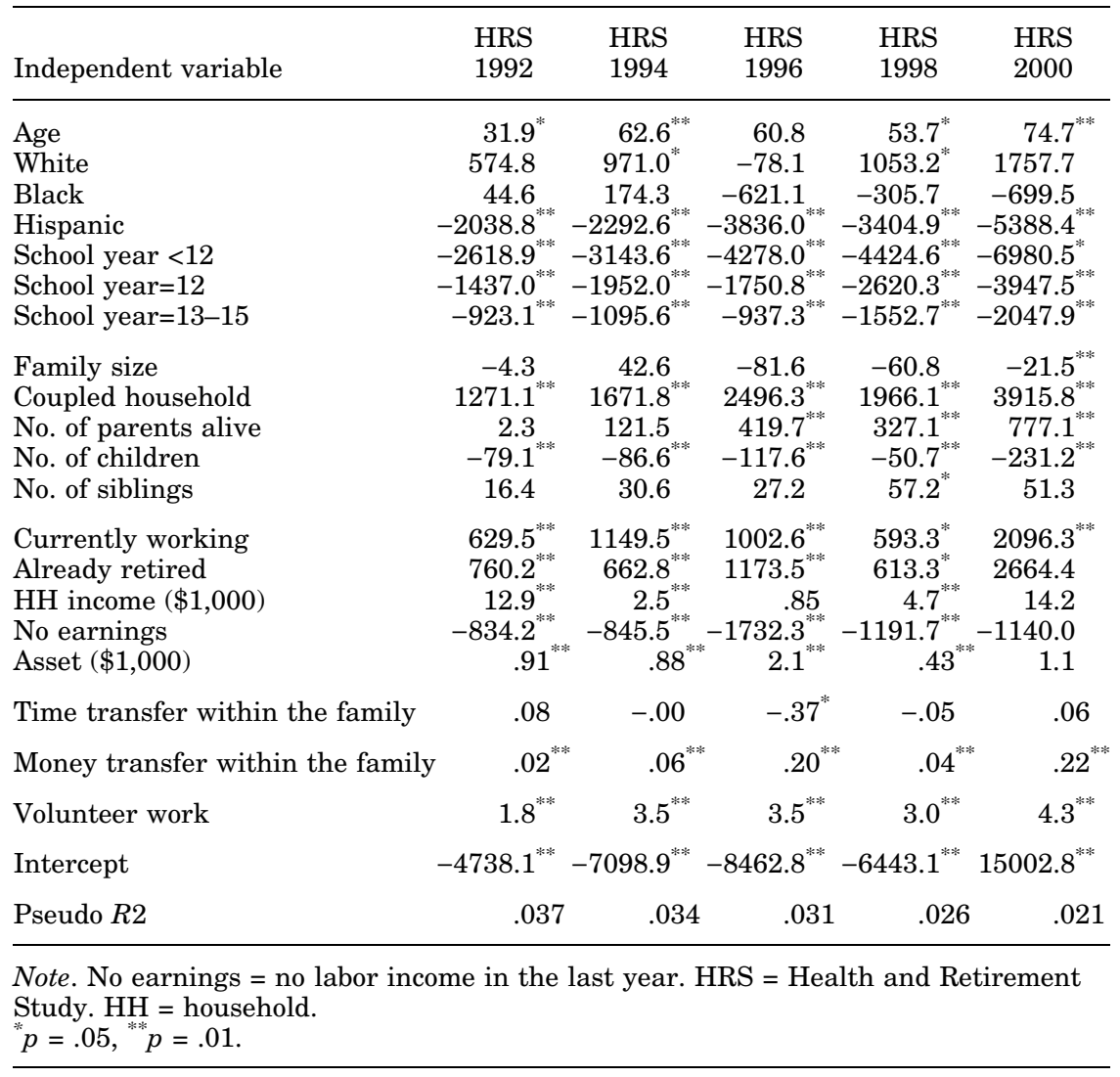

gesting that Hypothesis 1 induced from Table 2 was probably not valid. Alternatively, all four Level-2 cross-effects were zero, indicating that there was a boundary for one type of transfer to impact another type of transfer. Another interesting result from Table 8 was that the cross-effects were symmetric, suggesting that a household probably made a joint decision on the transfers within the family and beyond the family, and made a joint decision on the time transfer and the financial transfer. 


\section{Honggao Cao}

TABLE 8

Cross-Effects of the Time and Financial Transfers Shown in the Single Wave Models

\begin{tabular}{|c|c|c|c|c|}
\hline \multirow[b]{3}{*}{ Type } & \multicolumn{4}{|c|}{ Model } \\
\hline & \multicolumn{2}{|c|}{ Time } & \multicolumn{2}{|c|}{ Money } \\
\hline & $\begin{array}{l}\text { Within the } \\
\text { family }\end{array}$ & $\begin{array}{l}\text { Beyond the } \\
\text { family }\end{array}$ & $\begin{array}{l}\text { Within the } \\
\text { family }\end{array}$ & $\begin{array}{l}\text { Beyond the } \\
\text { family }\end{array}$ \\
\hline \multicolumn{5}{|l|}{ Time } \\
\hline Within the family & $\mathrm{x}$ & $+*$ & $+{ }^{* * *}$ & 0 \\
\hline Beyond the family & $+*$ & $\mathrm{x}$ & 0 & $+* *$ \\
\hline \multicolumn{5}{|l|}{ Money } \\
\hline Within the family & $++^{* *}$ & 0 & $\mathrm{x}$ & $+* *$ \\
\hline Beyond the family & 0 & $+{ }^{* *}$ & $++^{* * *}$ & $\mathrm{x}$ \\
\hline
\end{tabular}

Note.$+=$ positive cross-effect, $0=$ no cross-effect, $\mathrm{x}=$ not relevant for the cross-effect. ${ }^{*} p=.05,{ }^{* * *} p=.01$.

\section{Models With Pooled Data ${ }^{9}$}

Regression results were not very different when the models were estimated with the HRS 1992-2000 data pooled together (Tables 9 and 10). Several important points need to be emphasized, however.

First, the race/ethnicity effect became more evident than that in the single wave data models. Other things being equal, the households headed by those who identified themselves as Black or Hispanic tended to spend less time on family care, do less volunteer work, provide less financial assistance to the family members, and make less charitable donations.

Second, the household structure effects were more evident in the models predicting the within-family transfers and beyond-family financial transfer. Moreover, the effects of siblings that were absent in the single wave data models became statistically significant in all four transfer models.

Third, two Level-2 cross-effects emerged from the pooled models: the more the beyond-family time transfer, the more the within-family financial transfer, and vice versa. One possible explanation for this effect is that people who spend a lot of time away from the family may try to compensate family members by providing them with more money, whereas people who have more family care obligations may try to fulfill their volunteering work by making more monetary donations. 
Journal of Family and Economic Issues

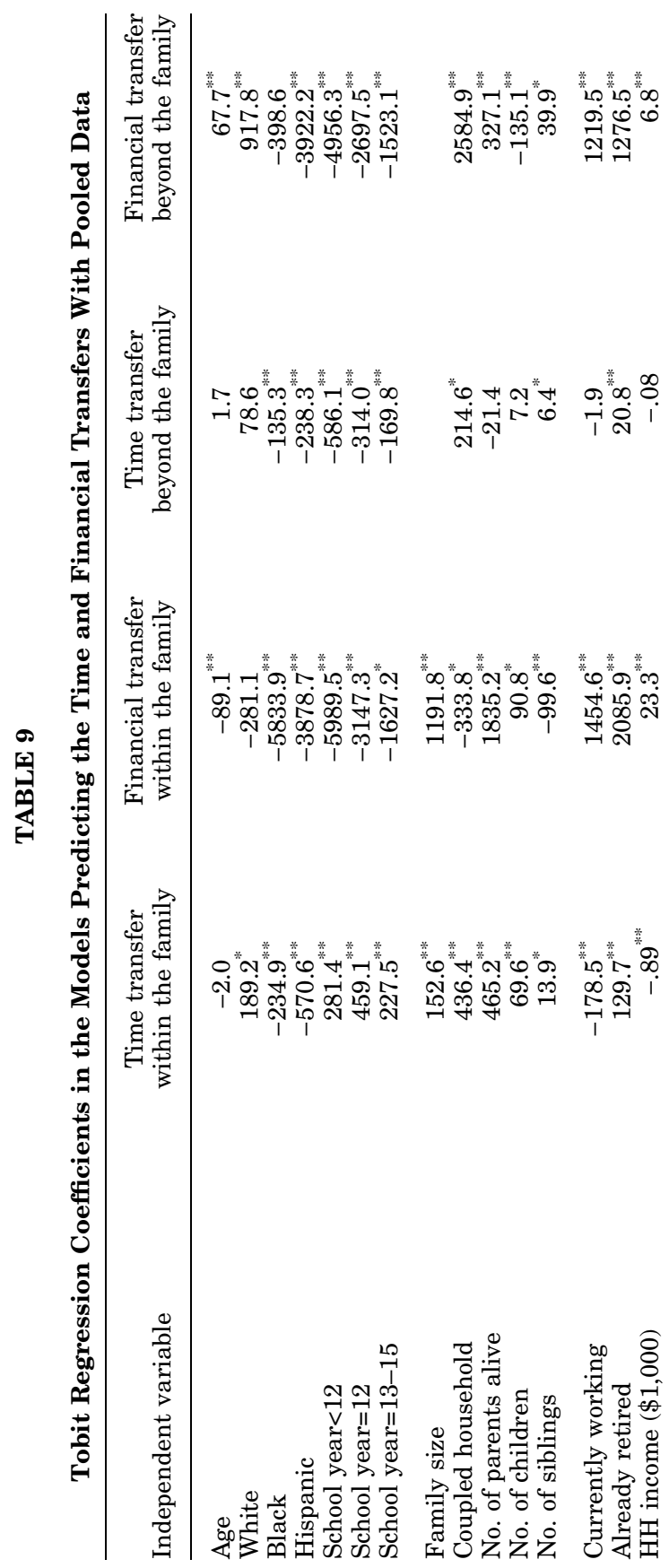




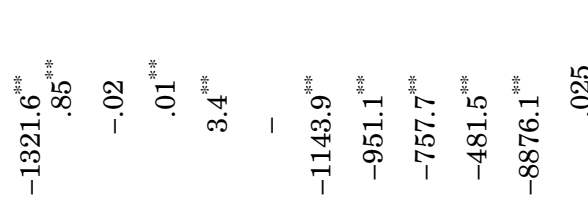

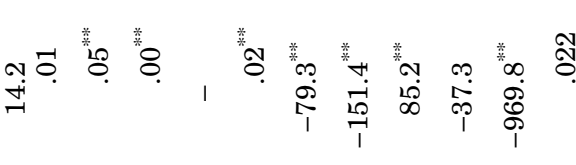

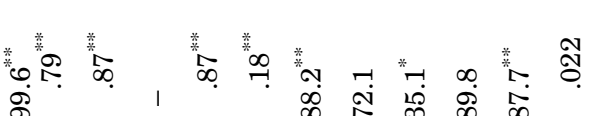

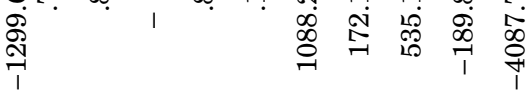

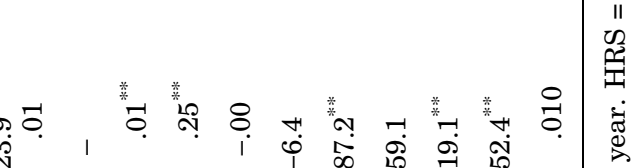
角

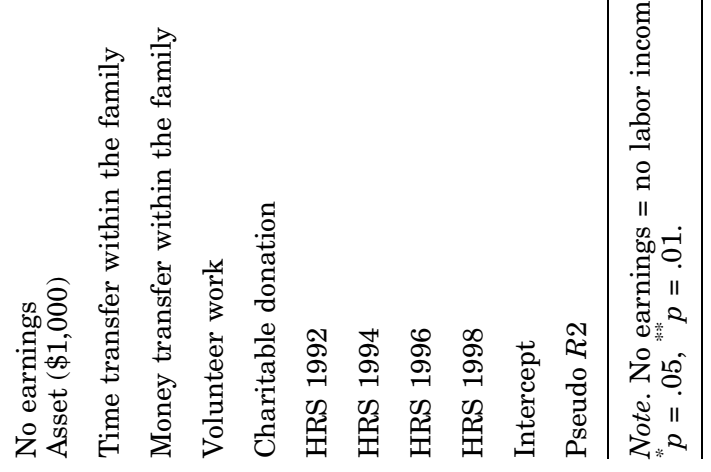


Journal of Family and Economic Issues

TABLE 10

Cross-Effects of the Time and Financial Transfers Shown in the Pooled Data Models

\begin{tabular}{|c|c|c|c|c|}
\hline \multirow[b]{3}{*}{ Type } & \multicolumn{4}{|c|}{ Model } \\
\hline & \multicolumn{2}{|c|}{ Time } & \multicolumn{2}{|c|}{ Money } \\
\hline & $\begin{array}{l}\text { Within the } \\
\text { family }\end{array}$ & $\begin{array}{l}\text { Beyond the } \\
\text { family }\end{array}$ & $\begin{array}{l}\text { Within the } \\
\text { family }\end{array}$ & $\begin{array}{l}\text { Beyond the } \\
\text { family }\end{array}$ \\
\hline \multicolumn{5}{|l|}{ Time } \\
\hline Within the family & $\mathrm{x}$ & $++^{* * *}$ & $++^{* * *}$ & 0 \\
\hline Beyond the family & $+{ }^{* * *}$ & $\mathrm{x}$ & $+* *$ & $+* *$ \\
\hline \multicolumn{5}{|l|}{ Money } \\
\hline Within the family & $+* *$ & $+* *$ & $\mathrm{x}$ & $+* *$ \\
\hline Beyond the family & 0 & $+{ }^{* * *}$ & $+{ }^{* * *}$ & $\mathrm{x}$ \\
\hline
\end{tabular}

Note $+=$ positive cross-effect, $0=$ no cross-effect, $\mathrm{x}=$ not relevant for the cross-effect. ${ }^{*} p=.05,{ }^{* *} p=.01$.

Fourth, as in the single wave data models, age was a statistically significant factor only in the models predicting financial transfers. As people got older, the financial transfers within the family tended to decrease over time, whereas the transfer beyond the family tended to increase over time. This finding suggested that Hypothesis 2 induced from Table 2 was probably valid, whereas Hypothesis 3 was probably not.

\section{Conclusion}

The empirical results from the HRS clearly indicate that the time and financial transfers within and beyond the family are closely related. The consistently positive and symmetric Level- 1 cross-effects suggest that the transfers within and beyond the family are not substitutes but complements, in the sense that families that are more willing to make within-family transfers are also more willing to make beyond-family transfers, and vice versa. In addition, within the same transfer destinations, families that are more willing to make time transfers are also more willing to make financial transfers.

Education plays a significant role in influencing a family's transfer behaviors. In general, people with higher educational levels tends to spend less time on family care but do more volunteer work, provide more financial assistance to family members, and make more chari- 


\section{Honggao Cao}

table donations. There are several possible explanations for the strong education effect on the time transfers within and beyond the family. First, well-educated people are perhaps more efficient household producers, so they have more time for outside activities. Second, welleducated people may be more valuable to non-profit organizations; demand for their service is higher. Third, well-educated people may be more knowledgeable about the importance of volunteering work and about where their expertise can be used.

Other things being equal, Black and Hispanic families tend to spend less time on family care, do less volunteer work, provide less financial assistance to the family members, and make fewer charitable donations. Although contradictory to some studies regarding ethnic differences in the propensity to give (e.g. the Twenty-First Century Foundation, 2003), this finding agrees with many others (e.g. Knapp \& Smith, 1995) and suggests that the minority populations still lag systematically in the generosity to help the people both within and beyond their families. Consequently, educating the minority groups about philanthropy and volunteerism $(\mathrm{P} \& \mathrm{~V})$ may have a great impact on unleashing new resources in the field of $P \& V$, as realized in some recent $\mathrm{P} \& \mathrm{~V}$ programs (e.g. the W. K. Kellogg Foundation's "Unleashing Resources for the Common Good Initiative" ${ }^{10}$ ) that target those groups.

The family structure, income, and wealth, as well as family members' labor market status are all important factors in a family's transfer decisions. It is not surprising that families make more withinfamily transfers when needs of family members for such transfers arise. In the meantime, wealthy families have the ability to provide more financial assistance to family members and make more charitable donations.

Family transfer decisions are probably made jointly as reflected by the symmetric nature of the cross-effects. To better understand family transfer behavior, therefore, researchers should not constrain their studies to either the within-family transfers or the beyond-family transfers. Instead, they should have a comprehensive model integrating the decisions about both groups of transfers. In this way, researchers on the transfers within the family may benefit from and contribute to studies on philanthropy and non-profit work. Members of the philanthropic community will also have a better understanding of the nature of giving and volunteerism, which may enhance future opportunities for such work. 
Journal of Family and Economic Issues

\section{Acknowledgment}

The author thanks Daniel H. Hill, Robert J. Willis, and anonymous reviewers for their constructive comments on an earlier version of this article. The author, however, is responsible for any possible errors.

\section{Notes}

1. In addition to the original sample, HRS also contains a sister cohort, AHEAD, for which data collection started in 1993. Further, two more cohorts, War Baby and CODA, were added to the study starting in 1998. For more information on the structure of the HRS, see Health and Retirement Study (1999).

2. According to the Current Population Survey (1983), a family household is a household maintained by a family-which is a group of two persons or more related by birth, marriage, or adoption-and any unrelated persons who may be residing there. A HRS household is a family household in the sense that, when a household has two respondents, they may just be partners. For simplicity, however, I will only refer to a HRS family household as "household."

3. For those interviewed in both the HRS 1994 and 1996, the actual interview months were used in making this conversion for the comparable measures in the HRS 1996. For those who were first interviewed in HRS 1996 or later, I assumed that the original HRS 1996 measures were about "the last 2 years" or 24 months. Conversions for the HRS 1998 or 2000 measures were done in the similar way.

4. Because people recall events over a more recent time period better than for a more distant time period, this strategy may introduce bias to the adjusted measure. According to Hill (1999), however, a linear relationship between the quantity of the transfer and the reference period may be a reasonable approximation here.

5. The within-family financial transfer does not include financial assistance to grandchildren as the information is not available in all the HRS waves studied.

6. Consider a positive transfer measure, $Y$, which is left-truncated at threshold $\alpha$.

$$
\begin{aligned}
E(Y) & =\operatorname{Pr}(Y \leq \alpha) * E(Y \mid Y \leq \alpha)+\operatorname{Pr}(Y>\alpha) * E(Y \mid>\alpha) \\
& \geq \operatorname{Pr}(Y \leq \alpha) * 0+\operatorname{Pr}(Y>a) * E(Y \mid>\alpha) .
\end{aligned}
$$

7. The first type of data limitation, or the data truncation issue, may be resolved with the help of certain statistical methods such as Tobit models, as discussed in the section "Cross-Effects in Regression Model."

8. For a two-respondent household, the demographic characteristics were of the respondent selected according to the following priority rules: (a) original HRS respondent, (b) the second respondent interviewed, and (c) male. The respondent chosen in this way will be conveniently called the head of the household.

9. I have also estimated a set of fixed effect models using the pooled data but found no significant differences in the cross-effect variables.

10. See http://www.wkkf.org. 


\section{Honggao Cao}

\section{References}

Andreoni, J., Gale, W., \& Scholz, J. (1996). Charitable contributions of time and money. Madison: University of Wisconsin-Madison, Department of Economics.

Auten, G., \& Joulfaian, D. (1996). Charitable contributions and intergenerational transfers. Journal of Public Economics, 59, 55-68.

Becker, G. (1974). A theory of social interactions. Journal of Political Economy, 82, 1063-1093.

Becker, G. (1991). A treatise on the family. Cambridge, MA: Harvard University Press.

Becker, G., \& Tomes, N. (1986). Human capital and the rise and fall of families. Journal of Labor Economics, 4(3 Part 2), S1-S39.

Bekkers, R. (2001). Giving time and/or money: Trade-off or spill-over? Retrieved September 28: 2004. From http://www.fss.uu.nl/soc/homes/bekkers/arnova0202.pdf.

Callen, J. (1994). Money donations, volunteering and organizational efficiency. Journal of Productivity Analysis, 5, 215-228.

Caputo, R. K. (2002). Adult daughters as parental caregivers: Rational actors versus rational agents. Journal of Family and Economic Issues, 21, 171-202.

Carlin, P. (2001). Evidence on the volunteer labor supply of married women. Southern Economic Journal, 67, 801-824.

Current Population Survey. (1983). Money income of households, families, and persons in the United States: 1981. Current Population Reports, Series P-60, No. 137, U.S. Department of Commerce, Bureau of the Census.

Current Population Survey. (2002). Volunteering in the United States, 2001. Retrieved May 22, 2004. From ftp://ftp.bls.gov/pub/news.release/volun.txt.

Dettingger, E., \& Clarkberg, M. (2002). Informal caregiving and the retirement timing among men and women: Gender and caregiving relationships in late midlife. Journal of Family Issues, 23(7), 857-879.

Health and Retirement Study. (1999). An overview of the health and retirement study components. Retrieved September 28, 2004. From http:/hrsonline.isr.umich.edu/ intro/sho_uinfo.php?hfyle=overview\&xtyp=2\#hrs.

Health and Retirement Study. (2002). Codebook for the HRS 2000 imputation file, Version 2. Retrieved September 27, 2004. From http://hrsonline.isr.umich.edu/meta/ 2000/impute/h2000icb.txt.

Hill, D. (1999). Unfolding bracket method in the measurement of expenditures and wealth. In J. P. Smith \& R. J. Willis (Eds.) Wealth, work, and health (pp. 64-86). Ann Arbor: University of Michigan Press.

Independent Sector. (2001). Giving and volunteering in the United States. Retrieved May 22, 2004. From http://www.independentsector.org/PDFs/GV01keyfind.pdf.

Jones, A., \& Posnett, J. (1991). Charitable donations by UK households: Evidence from the Family Expenditure Survey. Applied Economics, 23, 343-351.

Kitchen, H., \& Dalton, R. (1990). Determinants of charitable donations by families in Canada: A regional analysis. Applied Economics, 22, 285-299.

Knapp, M., \& Smith, J. D. (1995). Who volunteers and why? The key factors which determine volunteering. Retrieved September 27, 2004. From http://www.jrf.org.uk/ knowledge/findings/socialpolicy/SP75.asp.

Loury, G. (1981). Intergenerational transfers and the distribution of earnings. Econometrica, 49(4), 843-867.

Lune, L. S. V., Winter, M., Morris, E. W., Gutkowska, K., \& Jeżewska-Zychowicz, M. (1999). Interhousehold transfers of goods and services and reported well-being among Polish households. Journal of Family and Economic Issues, 20, 333-366.

MacDonald, M., \& Koh, S. (2003). Consistent motives for inter-family transfers: Simple altruism. Journal of Family and Economic Issues, 24, 73-97.

McClelland, R., \& Brooks, A. C. (2004). What is the real relationship between income and charitable giving? Public Finance Review, 32, 483-497. 


\section{Journal of Family and Economic Issues}

Menchik, P. L., \& Weisbrod, B. A. (1987). Volunteer labor supply. Journal of Public Economics, 32, 159-183.

Mulligan, C. (1997). Parental priorities and economic inequality. Chicago: University of Chicago Press.

Nordblom, K., \& Ohlsson, H. (2003). Bequest, gifts, and education: Swedish evidence on parents' transfer behavior. Retrieved May 22, 2004. From http://www.anst.uu.se/ henryos/bgedec03.pdf.

Pollak, R. (1985). A transaction cost approach to families and households. Journal of Economic Literature, 23, 581-608.

Schervish, P., \& Havens, J. (2003). How do people leave bequests: Family or philanthropic organizations? In A. H. Munnell \& A. Sundén (Eds.), Death and dollars: The role of gifts and bequests in America (pp. 130-167). Washington, DC: Brookings Institution Press.

Twenty-First Century Foundation. (2003). Vision news. Retrieved December 10, 2004. From http://www.21cf.org/VisionNewsWeb.pdf.

Williamson, O. (1979). Transaction-cost economics: The governance of contractual relations. Journal of Law and Economics, 22, 233-262. 